\title{
Time-series analysis of response rates: Alcohol effects on variability-contingent operants
}

\author{
LOWELL T. CROW and PAUL J. MCKINLEY \\ Western Washington University, Bellingham, Washington
}

\begin{abstract}
Albino rats were trained in a two-bar LAG-5 reinforcement schedule in which the previous five four-response sequences could not be repeated. Accounting for order, on different days, the animals were given ethanol $(0, .4$, and $.8 \mathrm{~g} / \mathrm{kg}) 10$-min prior to the operant sessions and measures were made of total responses per minute for $16 \mathrm{~min}$. Fourier transforms of the data for each animal showed that although alcohol diminished response rate, it did not diminish response variability. The data are compared with Fourier analyses of alcohol effects on CRF reinforcement schedules for which alcohol is shown to diminish both rate and variability of responding. The possible importance of this differential effect of alcohol on variability of responding is discussed.
\end{abstract}

As measured by uncertainty statistics, ethyl alcohol has been shown to diminish response variability in a number of tasks, including operant responding under continuous reinforcement (CRF) and fixed-interval (FI) reinforcement schedules (Crow \& Hart, 1983; Crow, McWilliams, \& Ley, 1979) and performance in a radial-arm maze (Devenport \& Merriman, 1983). With schedules that selectively reinforce response variability (Page \& Neuringer, 1985), however, alcohol does not appear to diminish uncertainty (Crow, 1988; Tennison, 1988).

The Fourier transform of data from the time domain to the frequency domain has become increasingly useful in the understanding of time-series events (Ramirez, 1985) but has been used sparingly in behavioral research. The present study represents an attempt to depict response-rate data, particularly response variability, from this unique perspective in the hope of gaining a better understanding of alcohol-induced stereotypy of behavior.

\section{METHOD}

\section{Subjects}

Sixteen male albino Sprague-Dawley rats bred at Western Washington University were used as subjects. The animals ranged in age from 90 to 100 days at the beginning of the experiment and were experimentally naive.

The rats were housed individually in suspended $7 \times 9 \times 7$ in. stainless steel cages with wire-mesh floors. The day/night lighting schedule was $12 \mathrm{~h}$ on and $12 \mathrm{~h}$ off. Temperature and ventilation were controlled centrally and kept at $70^{\circ} \mathrm{F}$. Purina Lab Chow was available ad lib. All animals received $30 \mathrm{~min}$ of free water in addition to that obtained in the daily experimental sessions.

Three, two-bar operant chambers (Gerbrands), modified for water delivery, were used in conjunction with three Atari $800 \mathrm{XL}$ personal computers, which were used both for programming contingencies and for on-line computation of $U$-values. Fourier analysis (Turbo Pascal Numerical Methods Toolbox) was done with a Pony XT personal computer.

Correspondence may be addressed to Lowell T. Crow, Department of Psychology, Western Washington University, Bellingham, WA 98225.

\section{Alcohol Doses}

Ten minutes prior to the session, a $10 \%$ aqueous solution of $95 \%$ ethanol was injected i.p. in an amount which was either 0.4 or $0.8 \mathrm{~g} / \mathrm{kg}$. Control injections were isotonic saline.

\section{Procedure}

The animals were put on a 23.5-h water-deprivation regimen and were manually shaped to the two-bar response by students enrolled in an undergraduate physiological psychology course. After the animal learned to press one of the levers, the preferred lever was removed and the rat was shaped to the other lever. When the rat demonstrated that it would press either lever, the animal was put on a LAG-1 contingency in which a four-response sequence of presses in any pattern was reinforced only if the sequence was different from the preceding sequence of four. After 2 days of LAG-1, a LAG-5 contingency was imposed wherein a sequence of four presses was reinforced only when it differed from the last five sequences of four. Each session lasted $30 \mathrm{~min}$ or a total of $\mathbf{2 5 0}$ responses (whichever occurred first), at which time response rates and uncertainty scores were computed on-line and collected on hard copy.

After a stable level of uncertainty scores was attained (usually after 3 to 5 days of LAG-5), alcohol treatments were begun. Treatments consisted of either ethanol or saline injections $\mathbf{1 0}$ min prior to the daily session. Each animal eventually received all three doses (i.e., one saline, one $0.4 \mathrm{~g} / \mathrm{kg}$ ethanol, and one $0.8 \mathrm{~g} / \mathrm{kg}$ ethanol) but in different sequences to counterbalance for order. After each dose, the animal was run for 5 consecutive days before receiving the next dose.

\section{RESULTS}

Data from 2 of the 16 animals were excluded from the final analysis because their average daily performance levels did not meet the minimum criteria of greater than $75 \%$ reinforcement or uncertainty scores greater than 0.80 .

ANOVAs between groups showed no significant differences between the saline and alcohol groups for either $U$ values $[F(2,26)=0.87]$ or percent reinforcement $[F(2,26)=0.25]$. There was a significant difference between groups for number of responses $[F(2,26)=12.68]$. A summary of these data is presented in Figure 1.

A Fourier transform of mean number of responses for each of the first 16 min shows the same data from a different perspective. Only 16 min for each session were used because the Fast Fourier Transform (FFT) requires an 

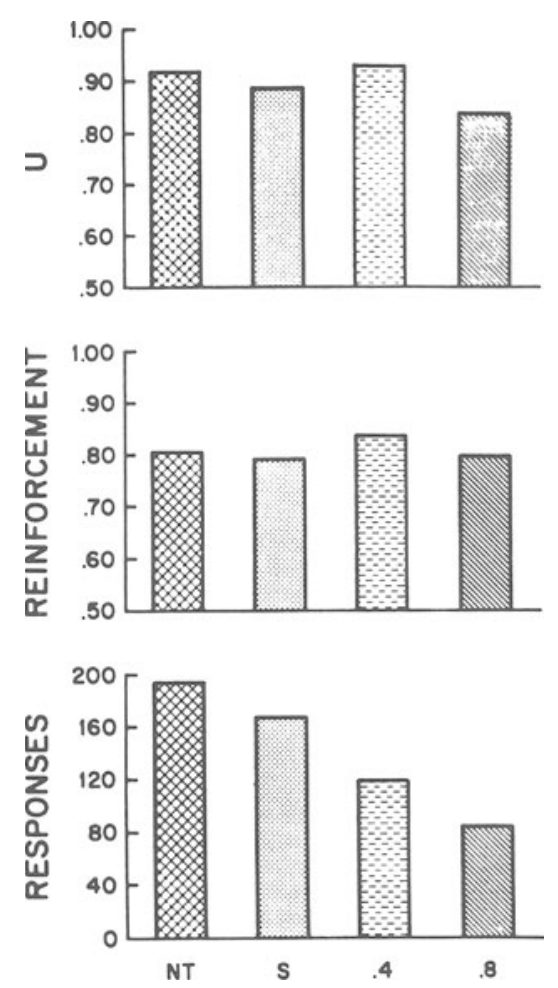

Figure 1. Means for each condition of uncertainty scores (U), proportion of sequences reinforced (reinforcements), and number of responses (responses). $\mathbf{N T}=$ no treatment, $\mathrm{S}=$ saline control; $.4, .8=\mathrm{g} / \mathrm{kg}$ alcohol.

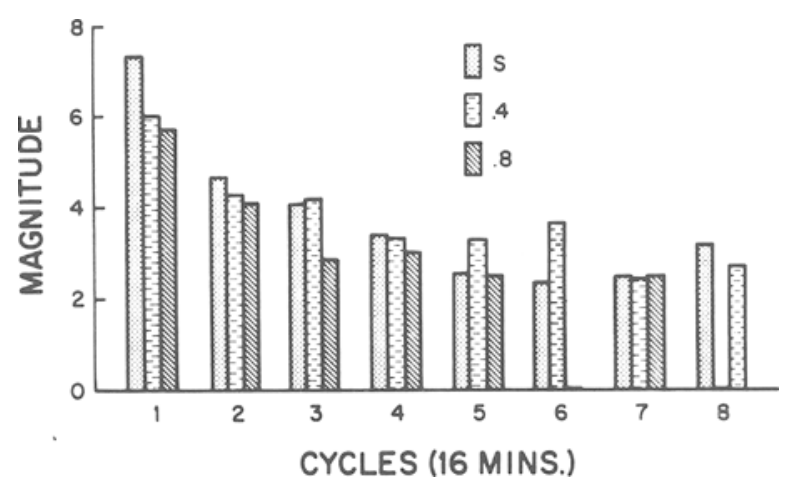

Figure 2. Frequency domain of response-rate data for each experimental condition under LAG-5 reinforcement contingencies.

$N$ which is a power of 2 . The positive-frequency magnitudes or RMS values of the real and imaginary parts of the FFT are plotted versus frequencies (cycles per $16 \mathrm{~min}$ in Figure 2).

Figure 2 shows a predominant rate change of one cycle during the session. That is, the composition of the function (number of responses over time, in terms of sine and cosine waves) is predominately one cycle with greater frequencies of lesser magnitude. The mean magnitudes were
3.70, 3.71, and 3.05 for the saline and the $0.4-$ and 0.8 $\mathrm{g} / \mathrm{kg}$ doses, respectively. As an assessment of response variability, variances of the different magnitudes for the different frequencies for each experimental condition were determined. The variances for the conditions were 2.49 , 1.12 , and 1.51 for the saline and the $0.4-$ and $0.8-\mathrm{g} / \mathrm{kg}$ doses, respectively. There were no significant differences between either means or variances of the magnitudes.

However, compare these data to Fourier transformation of CRF rate data from Crow et al. (1979) (Figure 3). Although the dosage of alcohol was greater in that study$1.5 \mathrm{~g} / \mathrm{kg}$ - it can be seen that the CRF conditions are affected very differently by alcohol. The difference in both the mean and variance between the control and alcohol groups are much greater in the direction of a lower response variability for the alcohol condition. The variance of the alcohol group, 0.047, compared with the control-group variance of 5.47, reflects an $F$ of 116.38, which is significant.

\section{DISCUSSION}

In spite of an early finding in our laboratories that alcohol may increase response variability in LAG-5 performance in rats (Crow, 1988), the subsequent work of Tennison (1988) and the present study indicate otherwise; that is, that there is no effect on the rat's response variability of low doses of alcohol on LAG-5 responding. The differences in results may be due to a "ceiling effect" in the latter studies, as, due to more efficient training procedures, uncertainty scores attained by the animals were higher than those of the earlier study (Crow, 1988). In any case, the LAG-5 reinforcement schedule appears to present a special case, as alcohol decreases response variability for most tasks, but not in LAG-5 responding.

The Fourier analysis of the response-rate data supports the analysis based on the uncertainty statistic in that neither measure was significantly affected by alcohol. The basis for the differences in alcohol effects upon the different reinforcement schedules remains unclear, but may reflect brain activity unique to LAG-5 responding (Crow, 1988).

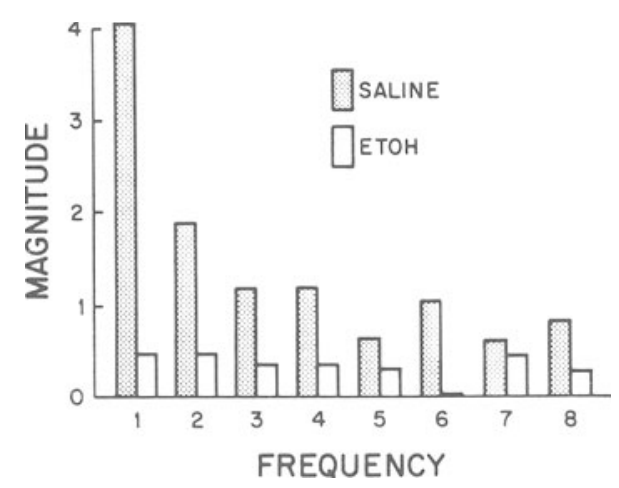

Figure 3. Frequency domain of responses-rate data for alcohol and controls under CRF reinforcement contingencies. (Adapted from "Relative stereotypy of water-ingestive behavior induced by chronic alcohol injections in the rat," by L. T. Crow, L. S. McWilliams, \& M. F. Ley, 1979, Bulletin of the Psychonomic Society, 14, 278-280.) 


\section{REFERENCES}

Crow, L. T. (1988). Alcohol effects on variability-contingent operant responding. Bulletin of the Psychonomic Society, 26, 126-128.

CROW, L. T., \& HART, P. J. (1983). Alcohol and behavioral variability with fixed-interval reinforcement. Bulletin of the Psychonomic Society, 21, 483-484.

Crow, L. T., McWilliams, L. S., \& Ley, M. F. (1979). Relative stereotypy of water-ingestive behavior induced by chronic alcohol injections in the rat. Bulletin of the Psychonomic Society, 14, 278-280.

DEVENPORT, L., \& MERRIMAN, V. (1983). Ethanol and behavioral variability in the radial-arm maze. Psychopharmacology, 79, 21-24.
PAGE, S., \& NeURINGer, A. (1985). Variability is an operant. Journal of Experimental Psychology: Animal Behavior Processes, 11, 429-452. RAMIREZ, R. W. (1985). The FFT: Fundamentals and concepts. Englewood Cliffs, NJ: Prentice-Hall.

TENNISON, L. (1988). The effects of contingency, alcohol, and previous training on behavior variability. Unpublished master's thesis, Western Washington University, Bellingham.

(Manuscript received May 5, 1989.)

\title{
Announcement
}

\author{
12th Biennial Psychology in the Department of Defense (DoD) Symposium \\ Air Force Academy near Colorado Springs \\ April 18-20, 1990
}

The Department of Behavioral Sciences and Leadership, United States Air Force Academy, will host the 12th Biennial Psychology in the Department of Defense (DoD) Symposium, April 18-20. This is the largest gathering of psychologists in the DoD, but civilian scholars and reseachers from across the spectrum of behavioral sciences are invited to participate. Papers and panel discussions cover such areas as personnel selection, training and testing, organizational development, human factors engineering, leadership, clinical psychology, military family, artificial intelligence, and military women and minority issues.

Further information about the symposium may be obtained by writing or calling Lieutenant Colonel Dave Porter (Symposium chair) or Major Lee Leber (Program chair), Department of Behavioral Sciences and Leadership, United States Air Force Academy, CO 80840-5701 (Telephone: 719-472-3860 or AV 259-3860). 